\title{
A Review on Techniques of Various Post-Harvest Treatments on Citrus spp
}

\author{
S. Azhagu Thirunavukkarasu*, Nangunuri Varun Kumar and Vijaya Rawat
}

Lovely Professional University, Phagwara, Punjab, India

*Corresponding author

\begin{tabular}{l} 
K e y w o r d s \\
$\begin{array}{l}\text { Post-Harvest } \\
\text { treatments, } \\
\text { Citrus spp }\end{array}$ \\
\hline Article Info \\
$\begin{array}{l}\text { Accepted: } \\
20 \text { October } 2020 \\
\text { Available Online: } \\
10 \text { November } 2020\end{array}$ \\
\hline
\end{tabular}

\section{Introduction}

According to CCRI 2015 (Central Citrus Research Institute), Citrus is cultivated In 114 countries across the globe, Of these, 53 countries commercially cultivate citrus, with a combined output of more than 115 million tonnes. China tops the list with 22.9 million tonnes on a production basis, followed by Brazil with 22.7 million tonnes and the USA with 10.4 million tonnes. India is in 4th place, with 10.48 million tonnes. Mexico placed 5th and 6th with 6.7 million tonnes and Spain 
with 6.5 million tonnes. Sweet orange (Citrus sinensis Osbeck), mandarin (Citrus reticulata Blanco), limes (Citrus aurantifolia Swingle), lemon (Citrus limon (L) Burm.f), grapefruit (Citrus paradise Macf.) and pummelo (Citrus grandis (L.) Osbeck) include commercial citrus fruits. CCRI 2015 (Central Citrus Research Institute). Sweet orange with a 64 percent contribution dominates the world citrus, mandarins $20 \%$ Limes $10 \%$ finally lemons, and the remaining $6 \%$ occupied by Grapefruit and further citrus fruits. Maintaining an amount produced of 10.48 million tonnes with an average productivity of 9.78 tonnes/hectare, the citrus region in India is 1.07 million ha. Total mandarin production in India is 3.25 million tonnes with an area of 0.32 million ha and a productivity of 10.16 tonnes/ha, while limes/lemons have an area of 0.21 million hectares with a production of 2.10 million tonnes and a productivity of 9.62 tonnes/hectare. Expansion has been reported over the last 20 years at an annual rate of 5.95 percent in area and 6.2 percent in production. There are some special characteristics of the Indian citrus industry, and unlike China and Japan, where citrus is mostly grown in humid subtropical climates, both mandarins and sweet oranges are grown in India under tropical climate conditions, except Kinnow and Khasi mandarin. In the humid tropical Vidarbha region of Maharashtra, where summer temperatures reach as high as 45-460 $\mathrm{C}$, the popular Nagpur orange (mandarin) is grown. With 278,000 ha of citrus in Central India, both Maharashtra and 1,28,000 ha of Andhra Pradesh in South India enjoy a distinct tropical climate where there is no well-defined low-temperature winter season. The Kinnow mandarin, however, shows strong promise and is commercially popular with distinct winter seasons in northern Indian states such as Punjab, Haryana, and Rajasthan coming under subtropical climates. Similarly, in northeastern hill states, typical mandaringrowing areas experience humid subtropical climates with heavy monsoon rainfall (summer) and low winter temperatures.

At present, Horticultural statistic data on citrus production is 10.48 million tonnes, with a maximum share of mandarins (3.25 million tonnes) followed by acid lime and lemons (2.10 million tons) and sweet orange (1.36 million tons). The production trend during 1992-93 to 2010-11 established increased production of citrus fruits. During the last 50 years (1961-2011), citrus production and area expanded more than nine-fold.

Apart from production post-harvest factors are practiced to enhance the storage and shelf life of fruit so various.

Post-harvest methods with usual synthetic waxes or inorganic fungicides, for instance, Imazalil (IMZ), Thiabendazole (TBZ), Sodium ortho-phenyl phenate (SOPP) and other effective ingredients had been used since past time and now still their usage is done at home from citrus fruit packaging. to preserve fresh fruit, control post-harvest degradation, and extend fruit life. However, the continuous use of these treatments has led to major problems in citrus, such as hygiene and environmental issues related to chemical residues or the proliferation of strains resistant to pathogens. Updated regulations in various countries are progressively putting a limit on usage of Agro-based chemicals since every export markets need more and more organic fruit every day, with even lower levels of waste than stipulated in a certified set of laws specified these circumstances, study is supposed to focus on expecting a situation where usual chemical fungicides are not obtainable. Here in this context, postharvest deterioration control is satisfactory with the adoption of Integrated Disease Management (IDM) programs based on a comprehensive understanding of pathogen biology and epidemiology and taking into 
account all pre-harvest, harvest factors, and after the harvest. crops that affect the incidence of the disease. Among the synthetic chemical antifungal treatments being studied around the world for achievable addition in the IDM program, By analyzing it is possible to investigate the progress of not poisonous antifungal coatings as a capable new tool to deal with 2 main problems in post-citrus loss of cases. your treatment. physiological problems and losses due to pathological problems.

\section{Usage of surface coatings and films in order of application natural antimicrobial's agents}

To prevent disease after harvest, natural antimicrobial agents can be used in a steam or liquid system mixed with surfactants in immersion tanks during the packaging process or in washing formulations (Mari et al., 2016). In practice, these compounds are processed individually, in sachets, in packaging systems, during storage, transport or even placing on the market, depending on the fruit and ability against environmental stress (temperature, humidity, $\mathrm{pH}$, oxygen light, etc.). Oxidative decomposition can affect these compounds, leading to the formation of free radicals and the development of unpleasant tastes and odors. This leads to an adverse effect on the shelf life, sensory properties, and acceptability of the products by the consumer (Ariyarathna and Karunaratne, 2016; Gómez-Mascaraque et al., 2016; Shishir et al., 2018). Therefore, to ensure the effective application of natural antimicrobials, it must be taken into account that their stability and bioactivity depend on their physicochemical properties (structure, molecular weight, solubility, and reactivity) and agro-industrial conditions of application (Kamil et al., 2015; Rodríguez et al., 2016; Shaaban et al., 2012). Therefore, their application has diversified in recent decades through the development of edible coatings and films, as these technologies provide an opportunity to reduce environmental risks and improve food quality (Fernández et al., 2017; Marín, Atarés and Chiralt, 2017; Ponce et al., 2008; Ramos- García et al., 2010; Yuan et al., 2016).

These techniques combine the principles of physical, chemical and biological methods and include the use of GRAS ingredients of various natures, such as salts, peptides, small proteins, EO, PPhs, and other plant extracts (Aloui et al., 2014; Mari et al., 2016; Ponce et al., 2008), Antagonistic microorganisms (González-Estrada et al., 2017; Parafati et al., 2016) and others.

The edible coating creates a modified atmosphere by forming a barrier against gases $\left(\mathrm{O}_{2}, \mathrm{CO}_{2}\right.$, and water vapor), reduces the rate of respiration and weight loss during storage and transportation, slowing down the aging process of the fruit (Ramos-García et al., many biological materials, including polysaccharides, proteins, lipids and mixtures thereof, also taking into account the morphological and physiological characteristics of the products and their condition such as menopausal or non-climatic fruits. The properties of films (transparency, transparency, stability, etc.) the antimicrobial action will depend on biopolymers and high biological value (HBVC) characteristics (Marín et al., 2017; Yuan et al., 2016).

For example, the antifungal activity of some natural additives added to edible hydroxypropyl methylcellulose coatings against B. cinerea and $\mathrm{A}$. alternate has been shown in vitro on cherry tomatoes (Fagundes et al., 2013), while grapefruit extract EO or grapefruit with alginate coatings have been used successfully for canning grapes (Aloui et al., 2014). Similarly, edible films and chitosan coatings are promising systems that 
will be used as carriers of EOs and PPhs in post-harvest applications due to their antioxidant and antimicrobial activity. This combination can provide enhanced additive or synergistic interactions, with greater efficacy against fungi and food bacteria in food systems than pure films and coatings (ÁvilaSosa et al., 2012; Yuan et al., 2016).

For example, Bautista-Baños et al., (2003) evaluated the fungicidal impact of chitosan 2.5 percent and Aqueous extracts of cinnamon apple leaves, papaya leaves, and seeds based on developmental growth of $C$. gloeosporioides in the fruit of papaya. In in vitro tests, the combination of $2.5 \%$ chitosan with all extracts had an improved fungistatic effect, while in vivo studies the fight against anthracnose was achieved with $1.5 \%$ of chitosan. In addition, changes in the hyphae and spore development of $F$. oxysporum sp. gladioli and $R$. stolonifera and cell lysis of $A$. alternata have been observed after treatment with chitosan and a mixture of natural products (Bautista-Baños et al., 2012). In addition to this, Ávila-Sosa et al., (2012) revealed the antifungal effects of edible films of chitosan, amaranth, and starch with Mexican oregano oil $(0.5 \%)$ against $A$. niger and $P$. digitatum.

In the host system / antimicrobial compound/pathogen complex, many biochemical processes can occur with different effects on the biological activity of the antimicrobial compound. Pathogens are less likely to develop resistance against the mixture of compounds. Besides, the compounds present in the coatings can act as resistance elicitors through different mechanisms mediated by the host tissue (Yuan et al., 2016). For example, the combined coating could control the diffusion of EO vapor and reduce structural changes or loss of HBVC. Coatings, films, and microcapsules are more cost-effective because small volumes are applied, product contamination is avoided and prolonged action is assured. The use of small volumes guarantees efficient preservation of products without altering their sensory properties (Cortés-Higareda et al., 2019; Ezhilarasi et al., 2013; Kamil et al., 2015; Parafati et al., 2016; Wenchao et al., 2019).

Also, from a business point of view, the implementation of new coating technologies does not generally require the acquisition of new equipment or space, as many packages of fresh produce already use waxing equipment (Fernández et al., 2017; Mari et al., 2016). In addition to this, greater emphasis has been placed on developing films from new natural biopolymers currently, due to the growing demand for sustainable food production and opportunities to open up new markets from non-agricultural products. Recently, the use of conventional raw materials (tubers, rice, amaranth, and quinoa) has made it possible to obtain films and coatings with good mechanical and barrier properties (Mari et al., 2016).

Ron porat et al., (2005) tested the reduction of post-harvest disturbance in citrus fruits through modified atmosphere packaging and noted that citrus fruits are not relatively delicate but it has the possibility to be kept safer for a longer period up to six to eight weeks. Though, the progress of diverse types of cortical disorder restricts the possibility of further storage and leads to huge business losses. (HF) as well as other skin disorders not related to the cold. Such as crust decomposition, rod end crust decomposition (SERB), and button tissue compression and decomposition (aging). In all cases, microperforated membranes $(0.002 \%$ of the perforated area) to be regulated Carbon dioxide and oxygen concentrations at 2 to 3 and 17 to18 percent correspondingly, be further efficient in wrapping on limiting the 
expansion of membrane disorder than the perforate membranes. (Macro perforated area $0.06 \%$ ) that regulate the Carbon-dioxide and Oxygen concentrations of 0.2 to 0.4 and 19 to $20 \%$ correspondingly, among these 2 types of wrapping, the relative humidity $(\mathrm{RH})$ was 95\%. No further considerable dissimilarity was found among the efficiency of the polyethylene (PE) and XF packaging, although XF prevents the bags from condensing in water. Overall, XF microperforated and macro-perforated packaging reduced non-cold cortical disorders (skin deterioration, SERB, and aging) by 75 and $50 \%$ after storage for 5 weeks at $5{ }^{\circ} \mathrm{C}$ and 5 days storage, respectively. 60 and 40 percent tangerines in Mineola. Similarly, XF microperforated and macro-perforated packaging reduced IC growth by 70 and 35\% later than six weeks of freezing storage space at 7 degree Centigrade and 5 days after 5 degrees Centigrade storage, in that order, in oranges "Shamut" and 75 and 45\%, respectively, in Star Ruby With grapefruit. In totaling, storing packaged "carbonated" oranges at a high RH temperature, $95 \%$ also limits the skin blemishes by $40 \%$ to $50 \%$, comparable to the outcome of macro-perforated membranes. And by this we came to know that Modified atmosphere packaging MAP limits the citrus skin membrane development during 2 ways of action in citrus fruits: the second, especially for microfiber film, is to maintain a modified atmosphere with low levels of $\mathrm{CO}_{2}$ and $\mathrm{O}_{2}$.

Abhay Bisen et al., (2010) conducted experiments to evaluate the effect of chemical coating and oil coating on the shelf life increment of kagzi lime fruits. The fruits were physiologically obtained in the light green ripening point and processed with different concentrations of chemicals, namely calcium chloride, potassium permanganate, and food coatings, namely (coconut, mustard, sesame oil, Himashima oil and liquid paraffin). Back after the processing, the fruit was stored in ambient conditions $\left(25-30{ }^{\circ} \mathrm{C}, 60-70 \% \mathrm{RH}\right)$ On the $18^{\text {th }}$ day and PLW, various physical and chemical parameters such as fruit retention, TSS, acidity, and acidity were analyzed. Ascorbic acid content and sensory properties, the results obtained are the emulsion coating of edible oil, especially coconut oil, had a significant effect $(\mathrm{p} \leq 0.05)$ on physiological weight reduction $(9.67 \%)$ and maximum retention of marketable fruit (70\%), Total soluble solids $(8.43 \%)$, vitamin c (49.93 mg / $100 \mathrm{ml}$ juice), acidity (1.52\%) and juice content $(42.34 \%)$ in fruits. Similarly, the use of an emulsion coating of this oil is acceptable for sensory action parameters such as the appearance, taste, taste, appearance, and absence of fungi and their growth up to 18 years. Storage day. Whereas, sesamum oil and mustard oil coating exhibited lesser post-harvest life due to the appearance of brownish spots on the surface of fruit ultimately, which deteriorated the physicochemical composition of the fruit. In the case of the occurrence of the microbial population on the surface of fruits, it was observed that pure coconut oil coating delay the appearance of moulds up to 18 days of storage, while untreated fruits were affected by moulds after 12 days of storage.

Khamis Youseff et al., (2012) conducted a trial on Control of storage diseases of citrus by pre and postharvest purpose of salts and stated that the action of sodium bicarbonate (SB), sodium carbonate (SC), sodium silicate (SS), potassium bicarbonate (PB), potassium carbonate (PC), potassium sorbate (PS), calcium chloride (CC) and calcium chelate (CCh) on 'Comune' clementine and 'Valencia late' orange fruit was experimented against naturally occurring post-harvest decay. Three methods were used to apply 1) aqueous salt solutions $(2 \%)$ by spraying before harvesting, 2) By dipping after harvesting, and 3) By mixing pre- and post-harvest applications. After two months, decay was measured at $4 \pm$ 
1degree Centigrade (oranges) or $6 \pm 1$ degree Centigrade (clementines) and 95-98\% RH, followed by 7 days of shelf life at $20 \pm 2$ degrees Centigrade. Preharvest sprays and the mixture of pre- and post-harvest applications were more effective than post-harvest dipping for both species in suppressing decay. Concerning preharvest application, in contrast to water treatment, many salt completely limits the occurrence of spoilage. That is, SC and PC in both species, SS in "Late Valencia" orange. Both salts were less rot in the application compared to water quality adjustments and were beneficial with an efficacy range of $66-100 \%$ and $78-100$ percent for oranges and clementines, respectively. The behavior was generally less pronounced when salt is added after harvest, SC and PC are most effective in both organisms. In the in-vitro trial minimum inhibitory concentrations (MICs) reached $0.25 \%$ SB, SC, PB, PC, PS, and SS for both Penicillium digitatum and $P$. italicum In contrast to water management, the filamentous fungal population of fruits Once in the field, the double treatment was reduced, but no statistical variation was observed for post-harvest application. Comparatively on results of the application of salts on site must be considered a helpful strategy to be incorporated in an integrated way of approach to citrus disease control after harvest.

Research on pesticide residues reported in citrus To ensure the safety of citrus before and after harvest, pesticides, and other chemicals can be used to manage widespread mold or unwanted lot of insects (Didier Ortelli et al., 2005). Citrus examining done to resolve the level of pesticide residues. Two other multi-analytic ways with a sample test to more than 200 diverse fungicides, insecticides and acaricides. In the year 2003, overall 240 varieties of citrus fruits, such as lemon, orange, mandarin, grapefruit, lime, pomelo, and kumquat, taken from various markets in the Geneva area.95\% from 164 samples found with same pesticides and in the 38 various compounds are identified, the number of their hold over the conventional, the most on account of the height of the character, in the eyes of the two positive samples with a $36 \%$ to $70 \%$ of the harvest, fungicides, and set of examples of like thiabendazole and imazalil. There were only 3 exceeded MRLS in Switzerland. And Fiftythree models are sold through, they had written indication "No post-harvest treatment." There are no standard principles exceeded by the Swiss MRL pensonazole chloroprifrifo and 18 (34\%) indication is because they do not meet significant amounts of fungicide which were found in the fruit. in short, there are 23 kinds of certified organic farming can be experimented with. take the following examples, which are a small amount of the supply of pesticides, and the rest doesn't include the pesticides

Ladaniya (2010) review of machine-based automated systems using citrus images for citrus control post-harvest handling. Several postharvest handling practices are applied to the fruit after arriving at the packinghouse after harvesting, especially when it is intended for consumption as fresh fruit. On a roller elevator that transfers the fruit to the washing machine, the first inspection is normally performed. International materials and rotting, cut and very-bad-quality fruits are extracted at this stage. Fruits are then washed and, if needed, a fungicide can also be applied. Later, various procedures are applied, including rinsing, waxing, and briefly kept in cold storage. These operations may, however, be changed under some circumstances, such as when the fruit is harvested while the skin is still green (but it is completely ripe internally) and then a degreening process is required. The degreening process depends on the colour at harvest, so it is important to sort by colour (Ladaniya, 2010). It depicts oranges in 
various shades, ranging from green to brown. Later, when the fruit is to be delivered to the market, the entire harvest is inspected and sorted into commercial categories to ensure that only the fruit reaches the customer with the minimum quality specifications. Also, to increase income, a range of criteria must be grouped into commercial categories, which have a certain effect on the price the buyer is willing to pay for the product, such as size or colour. External inspection was conducted visually by qualified staff in the past and lessautomated facilities, and calibration was carried out using a drop-roll sizer to sort the fruit, typically in increasing sizes, according to the equatorial diameter. They currently rely on automated inspection systems to deal with the inspection of the enormous amount of fruit handled by packinghouses (sergio Cubero et al., 2016)

Lili Deng et al., (2015) argued that the effect of oligocytosan treatment on anthracnose disease on citrus fruits (Citrus sinensis L. Osbeck) Colletotrichum gloeosporioides is susceptible to infection during post-storage, which rapidly decreases the sensory and nutritional quality of the fruit. The capacity of treatment with oligochitosan to control C. Citrus fruit gloeosporioids has been studied during storage, and possible underlying mechanisms have been explored. Compared with their respective monitors, disease incidence and lesion diameter were lower in oligochitosan-treated fruits. There was an increased content of lignin, hydroxyproline rich glycoprotein (HRGP), hydrogen peroxide ( $\mathrm{H} 2 \mathrm{O} 2$ ), ascorbate, glutathione, complete phenol, and flavonoid compounds in the fruits dipped in oligochitosan. Furthermore, superoxide dismutase (SOD, EC 1.15.1.1), catalase (CAT, EC 1.11.1.6), peroxidase (POD, EC 1.11.1.7), polyphenol oxidase (PPO, EC 1.14.18.1), ascorbate peroxidase (APX, EC 1.11.1.11) and $\beta$-1, 3-glucanase (GLU, EC 3.2.1.39) enzymatic activities are also observed. In citrus fruit peels, all of which were associated with the onset of disease resistance induced, also increased. Those results suggested that treatment with oligochitosan could induce citrus fruit disease resistance to C. Penz gloeosporioides. Oligochitosan may be a possible alternative to traditional anthracnose post-harvest control methods in citrus fruit.

Wilma du ploy et al., (2009) reported on Preserved coatings with essential oils as an alternative method to synthetic fungicides upon post-harvest citrus management of Commercial StaFresh series coatings (SF865MS, abbreviated MS1, SF875MS, abbreviated MS2) and the organically suitable formulation of Carnauba Tropical $₫$ were used. Instead of a high-shine coating, the MS1 mid-season coating was used to add a lower solid content to the rind-sensitive fruit. A control of MS2 was applied as this was used for their export consignments by the packed house. In Letsitele (Limpopo Province, South Africa), approximately 2.4 tonnes of untreated, freshly harvested 'Tomango' fruit were obtained from R10 Citrus and processed in the packhouse on the same day in May 2008. Seven experimental and two control treatments were used to separate the sorted fruit. Nine cartons (average $15 \mathrm{~kg}$ size-sorted fruit per carton) were included in each procedure. The control treatments were performed by dipping the fruit into a mixture of Imazalil (500 L / L) and guazatine (1000 L / L), followed by MS1 and MS2 spray application, respectively. The experimental treatments consist of Carnauba Tropical ${ }^{\circledR}$ or MS1, respectively, modified with Lippia 2500 L / L oil, peppermint oil, lemon, or R - (-) carvone, without the addition of synthetic fungicides. Treatment consisting of $\mathrm{R}-(-)$ carvone-modified Carnauba Tropical ${ }^{\circledR}$ was omitted in this study. The treated fruits are packed in commercial boxes, weighed, and stored at $10^{\circ} \mathrm{C}$. All boxes were weighed after 
30 days in refrigerated storage, followed by 1 week at room temperature $\left(22^{\circ} \mathrm{C}\right)$. The incidence of the disease is assessed by visual inspection of the entire contents of each box. Weight loss was recorded and the overall quality of three boxes of each treatment was assessed. Ten fruits were randomly selected from each box, cut in half and the color of the pulp (Lab) determined using a chromometer CR-400/410 (Konica Minolta, Narich, Johannesburg, South Africa). $3 \mathrm{~kg}$ of fruit was randomly selected and pressed from each box. The juice was weighed and used to determine the $\mathrm{pH}$, total soluble sugar, and titratable acidity as described above. Five factory workers involved in routine juice extraction were used to assess the flavor of the juice. The presence or absence of foreign flavors is registered. To determine the shelf life of the remaining fruit, the boxes are left at room temperature for an additional 30 days before being re-evaluated as described above and significant results are noted.

Among the plant extracts that favor the development of efficient management strategies against microbial contamination, EOs have been the most investigated compounds among other antimicrobials (Kumar and Kudachikar, 2018; Mary et al., 2016; Rao et al., 2019).

Laura Maryoris Aguilar-Veloz et al., (2019) reported on The use of natural antimicrobial agents is an attractive ecological alternative to the synthetic fungicides applied to control pathogens during postharvest. To improve industrial production systems, postharvest research has evolved toward integration with science and technology aspects to promote the application of essential oils and polyphenols as antimicrobial agents, against phytopathogens and foodborne microorganisms during postharvest. Besides that, it is to highlight the use of coating and encapsulation techniques as emerging methods that improve their effectiveness. The integral knowledge about the vegetable systems, molecular mechanisms of pathogens, and mechanisms of these substances would ensure more efficient in vitro and in vivo experiences. Finally, the cost-benefit, toxicity, and ecotoxicity evaluation will be guaranteed the successful implementation and commercialization of these technologies, as a sustainable alternative to minimize production losses of vegetable commodities.

Daniel Valero et al., (1998) stated that After vacuum infiltration with $1 \mathrm{mM}$ of putrescine and $1 \mathrm{mM}$ of calcium chloride, fruit firmness, free polyamine levels (putrescine, spermidine, and spermine), abscisic acid ( ABA), and colour index were determined in lemon fruit at two maturing stages (at colour break and completely yellow). Compared with the control fruit in stage 1 lemons, both treatments greatly improved fruit firmness. During storage, putrescine treated fruits displayed higher firmness levels and lower weight loss than calcium-treated or nontreated fruits. Putrescin, spermidine, and spermine concentrations were higher for stage 1 than for stage 2 lemons, while for ABA, the opposite was observed. To maintain higher levels of endogenous putrescine and spermidine, putrescine treatment was the most successful, but only for stage 2 fruit. Putrescin and calcium treatments also postponed the colour Shift, which was connected to the lowest ABA levels listed.

It is concluded that among emerging technologies, edible coatings, films, and encapsulation techniques show improvements in processing efficiency. However, there are still many limitations that make it difficult to apply this technology as a control strategy. Based on this review, we have tried to list various post-harvest treatments for citrus species, as we need to be familiar with the latest techniques and some significant 
progress has been made in the biological and integrated management of post-harvest citrus diseases. Some bio fungicides are already on the market in many countries and are likely to be more readily available as they are registered in several regions. Other microbial antagonists will be available soon. Postharvest conditions create an ideal niche for microbial antagonists, as they are less sensitive to extreme weather changes and are often equipped with sophisticated climate control systems. However, so far only a few products with high biocontrol potential have been commercially available. Thanks to intensive research in various laboratories, the possibility of identifying strong microbes and developing biocontrol products suitable for commercial marketing seems great. On the other hand, it is unrealistic to assume that microbial antagonists have the same fungicidal activity as fungicides. Improved post-harvest microbial antagonist strategies describe techniques that reduce the use of traditional synthetic fungicides for the control of post-harvest citrus diseases, while including integration with other low-risk treatments to optimize performance. In developing these new strategies, emphasis must be placed on minimizing risks to human health and environmental toxicity. Research should provide the appropriate tools (microbial antagonists, natural ingredients, GRAS compounds, etc.) to develop a comprehensive citrus disease control strategy after harvest.

\section{References}

Food and Agriculture Organization of the United Nations. FAO Statistical Yearbook 2013. Available online: http: //www.fao.org/docrep/018/i3107e/i3107 e03.pdf (accessed on 22 September 2015)

Bisen, A., Pandey, S. K., and Patel, N. (2012). Effect of skin coatings on prolonging shelf life of kagzi lime fruits (Citrus aurantifolia Swingle). Journal of food science and technology, 49(6), 753-759.

Porat, R., Weiss, B., Cohen, L., Daus, A., and Aharoni, N. (2004). Reduction of postharvest rind disorders in citrus fruit by modified atmosphere packaging. Postharvest Biology and Technology, 33(1), 35-43.

Youssef, K., Ligorio, A., Sanzani, S. M., Nigro, F., and Ippolito, A. (2012). Control of storage diseases of citrus by pre-and postharvest application of salts. Postharvest Biology and Technology, 72, 57-63.

Cubero, S., Lee, W. S., Aleixos, N., Albert, F., and Blasco, J. (2016). Automated systems based on machine vision for inspecting citrus fruits from the field to postharvest - a review. Food and Bioprocess Technology, 9(10), 16231639.

Ortelli, D., Edder, P., and Corvi, C. (2005). Pesticide residues survey in citrus fruits. Food additives and contaminants, 22(5), 423-428.

Ladaniya, M. S. (2010). Citrus fruit: biology, technology, and evaluation. San Diego: Academic Press

Deng, L., Zeng, K., Zhou, Y., and Huang, Y. (2015). Effects of postharvest oligochitosan treatment on anthracnose disease in citrus (Citrus sinensis L. Osbeck) fruit. European Food Research and Technology, 240(4), 795-804.

Ariyarathna, I. R., and Karunaratne, D. N. (2016). Microencapsulation stabilizes curcumin for efficient delivery in food applications. Food Packaging and Shelf Life, 10, 79-86. https://doi. org/10.1016/j. fpsl.2016.10.005

Mari, M., Bautista-Baños, S., and Sivakumar, D. (2016). Decay control in the postharvest system: Role of microbial and plant volatile organic compounds. Postharvest. Biology and Technology, 
122, 70-81. $\quad$ https :// doi.org/10.1016/j.postharvbio.2016. 04 . 014

Gómez-Mascaraque, L. G., Hernandez-Rojas, M., Tarancon, P., Tenon, M., Gong, L., Li, T., and Jiang, Y. (2016). An inclusion complex of eugenol into $\beta$ cyclodextrin: Preparation, and physicochemical and antifungal characterization. Food Chemistry, 196, 324-330. https ://doi. org/10.1016/j.foodc hem.2015.09.052

Shishir, M. R. I., Xie, L., Sun, C., Zheng, X., and Chen, W. (2018). Advances in micro and nano-encapsulation of bioactive compounds using biopolymer and lipid-based transporters. Trends in Food Science and Technology, 78, 3460. https://doi.org/10.1016/j.tifs.2018.05.01 8

Kamil, C., Chen, O., and Blumberg, J. (2015). The application of nanoencapsulation to enhance the bioavailability and distribution of polyphenols. In C. Sabilov, H. Chen, and R. Yada (Eds.), Nanotechnology and functional foods effective delivery of bioactive ingredients (pp. 158-164). USA: IFT Press.

Rodríguez, J., Martín, M. J., Ruiz, M. A., and Clares, B. (2016). Current encapsulation strategies for bioactive oils: From alimentary to pharmaceutical perspectives. Food Research International, 83, 41-59. https ://doi.org/10.1016/j.foodr es.2016.01.032

Shaaban, H. A., El-Ghorab, A. H., and Shibamoto, T. (2012). Bioactivity of essential oils and their volatile aroma components: Review. Journal of Essential Oil Research, 24(2), 203-212. https : ://doi.org/10.1080/10412 905.2012.659528

Fernández, N. M., Echeverria, D. C.,
Mosquera, S. A., and Paz, S. P. (2017). Estado actual del uso de recubrimientos comestibles en frutas y hortalizas. Biotecnología en el Sector Agropecuario y. Agroindustrial, 15(2), 134-141. https ://doi.org/10.18684/ BSAA.

Marín, A., Atarés, L., and Chiralt, A. (2017). Improving the function of biocontrol agents incorporated in antifungal fruit coatings: A review. Biocontrol Science and Technology, 2, 23-28. https ://doi.org/10.1080/09583 157.2017.1390068

Ramos-García, L. M., Bautista-Baños, S., and Estrada-Carrillo, M. (2010). Compuestos antimicrobianos adicionados en recubrimientos comestibles para uso en productos hortofrutícolas. Revista Mexicana De Fitopatología, 28, 44-57.

Yuan, G., Chen, X., and Li, D. (2016). Chitosan films and coatings containing essential oils: The antioxidant and antimicrobial activity, and application in food systems. Food Research International, 89, 117-128. https ://doi.org/10.1016/j.foodr es.2016.10.004

Aloui, H., Khwaldia, K., Sánchez-González, L., Muneret, L., Jeandel, C., Hamdi, M., and Desobry, S. (2014). Alginate coatings containing grapefruit essential oil or grapefruit seed extract for grapes preservation. International Journal of Food Science and Technology, 49, 952959. https ://doi.org/10.1111/ijfs.12387.

González-Estrada, R., Carvajal-Millán, E., Ragazzo-Sánchez, J. A., BautistaRosales, P. U., and Calderón-Santoyo, M. (2017). Control of blue mold decay on Persian lime: Application of covalently crosslinked arabinoxylans bioactive coatings with antagonistic yeast entrapped. Food Science and Technology, 85, 187-196. https ://doi. 
org/10.1016/j.lwt.2017.07.019

Parafati, M., Vitale, A., Resstucia, C., and Cirvirelly, G. (2016). The effect of locust bean gum (LBG)-based edible coatings carrying biocontrol yeast against Penicillium digitatum and Penicillium italicum causal agents of postharvest decay of mandarin fruit. Food Microbiology, 58, 87-94. https://doi.org/10.1016/j.fm.2016.03.01 4

Ramos-García, L. M., Bautista-Baños, S., and Estrada-Carrillo, M. (2010). Compuestos antimicrobianos adicionados en recubrimientos comestibles para uso en productos hortofrutícolas. Revista Mexicana De Fitopatología, 28, 44-57.

Fagundes, C., Pérez-Gago, M. B., Monteiro, A. R., and Palou, L. (2013). Antifungal activity of food additives in vitro and as ingredients of hydroxypropyl methylcellulose-lipid edible coatings against Botrytis cinerea and Alternaria alternata on cherry tomato fruit. International Journal of Food, 166, 391398. https://doi.org/10.1016/j.ijfoo dmicro.2013.08.001.

Bautista-Baños, S., Hernández-López, M., Bósquez-Molina, E., and Wilson, C. L.
(2003). Effects of chitosan and plant extracts on growth of Colletotrichum gloeosporioides: Anthracnose levels and quality of papaya fruit. Crop Protection, 22, 1087-1092. https ://doi.org/10.1016/ S02612194(03)00117-0.

Cortés-Higareda, M., Ramos-García, M. L., Correa-Pacheco, Z. N., and Del Río, J. C. (2019). Nanostructured chitosan/ propolis formulations: characterization and effect on the growth of Aspergillus flavus and production of aflatoxins. Heliyon, 5(5), e01776. https://doi. org/10.1016/j.heliy on.2019.e01776

Ezhilarasi, P. N., Karthik, P., Chhanwal, N., and Anandharamakrishnan, C. (2013). Nanoencapsulation techniques for food bioactive components: A Review. Food and Bioprocess Technology, 6, 628647. https://doi.org/10.1007/s11947012-0944-0.

Wenchao, L., Zhang, M., and Bhandari, B. (2019). Nanotechnology - A shelf life extension strategy for fruit and vegetable. Critical Reviews in Food Science and Nutrition, 1-16. https ://doi.org/10.1080/10408 398.2019.1589415.

\section{How to cite this article:}

Azhagu Thirunavukkarasu, S., Nangunuri Varun Kumar and Vijaya Rawat. 2020. A Review on Techniques of Various Post-Harvest Treatments on Citrus spp. Int.J.Curr.Microbiol.App.Sci. 9(11): 2670-2680. doi: https://doi.org/10.20546/ijcmas.2020.911.324 